\title{
Psyllium and Laminaria Partnership-An Overview of Possible Food Gel Applications
}

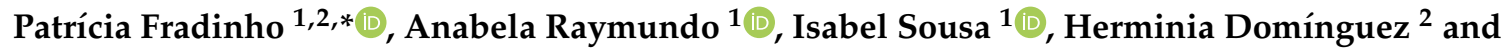 \\ María Dolores Torres ${ }^{2}$ \\ 1 LEAF_Linking Landscape, Environment, Agriculture and Food, Instituto Superior de Agronomia, \\ Universidade de Lisboa, 1349-017 Lisbon, Portugal; anabraymundo@isa.ulisboa.pt (A.R.); \\ isabelsousa@isa.ulisboa.pt (I.S.) \\ 2 Department of Chemical Engineering, Universidade de Vigo (Campus Ourense), Science Faculty, As Lagoas, \\ 32004 Ourense, Spain; herminia@uvigo.es (H.D.); matorres@uvigo.es (M.D.T.) \\ * Correspondence: pfradinho@isa.ulisboa.pt; Tel.: +351-213653246
}

Received: 11 September 2019; Accepted: 13 October 2019; Published: 16 October 2019

Featured Application: Laminaria-psyllium gels with distinct texture and rheological features, designed for a wide range of food applications.

\begin{abstract}
Seaweeds are a novel source of important nutritional compounds with interesting biological activities that could be processed into added-value products. In this study, two previously developed products obtained by Laminaria ochroleuca processing (liquid extract and a purée-like mixture) were processed with Psyllium gel to develop functional hydrogels. The optimization of the formulation and the characterization of the Laminaria-Psyllium gels in terms of their mechanical features have allowed the proposal of potential food applications. A beneficial interaction was found between Laminaria and Psyllium in terms of the reinforcement of texture and rheological properties. The obtained outcomes could provide new healthy gelling formulations with attractive properties to alleviate the growing market demand of eco-novel food matrices.
\end{abstract}

Keywords: kombu; edible brown seaweed; gels; Psyllium; Laminaria ochroleuca; autohydrolysis; mechanical properties

\section{Introduction}

Laminaria sp. are industrially used for alginate extraction (17.1-32\% $w / w$, dry basis) [1], a hydrocolloid with unique gelling abilities at low temperature and good heat stability, widely used as a thickener, stabilizer, and restructuring agent in the food, cosmetic, pharmaceutical, biomedical, and textile industries [2,3].

Mainly valued for alginate extraction, this natural resource presents other interesting compounds for human nutrition such as fatty acids, proteins, minerals [4], vitamins (A, C, D, B group, E, K, PP) [1], pigments such as carotenoids and polyphenols with proved antioxidant, hypoglycemic, antitumoral, and antimicrobial activities [5,6]. Due to their high content in biologically active compounds, seaweeds, and especially Phaeophyceae (brown algae), have great potential to act as a functional food and as a food ingredient $[7,8]$.

Psyllium (Plantago ovata) is an annual plant found mainly in India and Pakistan, but also on Madeira Island (Portugal) due to its subtropical climate. Used in traditional medicine for centuries, Psyllium husk has gained more attention by the scientific community since its health allegation was approved by the Food and Drug Administration in 2012 [9] regarding its benefits in reducing the risk 
of coronary heart disease. These features come from its high soluble fiber composition, which has the capacity of absorbing up to $15 \mathrm{~g}$ of water per $\mathrm{g}$ of Psyllium [10].

Psyllium husk is composed of $85 \%$ arabinoxylan, a neutral highly branched polysaccharide with about $35 \%$ of non-reducing terminal residues and a $15 \%$ non-polysaccharide fraction [11]. It has applications as an edible coating [12] and drug delivery [13].

Innovation in food and feed production is a reality and a tendency for the upcoming years, whether this is the use of poorly exploited raw materials, the reformulation of foods based on green and sustainable technologies, or "back to tradition". Many of the food and feed industries' products are gels (e.g., yoghurt, puddings, confectionery products, pasta, pet food, among others) or present gelling agents in their formulation (cream cheese, sauces, ... ), making gel-systems a growing market.

Among the edible biopolymers, the use of plant seed mucilages namely chia and flax seed $[14,15]$ are one of today's trends. Aside from the sustainability issue, these ingredients also have health benefits such as the regulation of colonic microbiota, reduction of hyperlipidemia, anti-inflammatory effect, control of glycemic response, and control of satiation [16]. Due to their technological properties, these biopolymers are often used in the food industry as texturizing agents.

To our knowledge, the gel forming ability of the combination of L. ochroleuca-Psyllium has not been previously investigated. Therefore, the interaction between Psyllium husk gel and the edible brown seaweed Laminaria ochroleuca, either in its liquid fraction or its purée-like mixtures, with Psyllium will be studied, taking advantage of both these poorly exploited natural resources. The aim of the present work is to lay the foundation for a systematic textural and rheological description of Laminaria-Psyllium gels, focusing on their mechanical features intended for future food applications.

\section{Materials and Methods}

\subsection{Raw Materials}

Dehydrated Laminaria ochroleuca (Algas Atlánticas Algamar, S.L., Pontevedra, Spain) was milled and sieved to two different particle size powders ( $0.25-2 \mathrm{~mm}$ and $<0.25 \mathrm{~mm}$ diameters). Psyllium husk of Indian origin (Solgar, lot 107028-01, Leonia, NJ, USA) was purchased at the local market, milled (Pulverisette 14 Premium, Fritsch, Idar-Oberstein, Germany) and sieved to 160-315 $\mu \mathrm{m}$.

For comparison purposes, commercial references were used, namely baby food (purée), guacamole (purée), fruit jam (gel), jelly gum (rubbery solid), pâté (liver paste), and pet food (moistened feed, pâté like).

\subsection{Formulations Development}

\subsubsection{Laminaria ochroleuca Sample Production}

Focusing on the full valorization of L. ochroleuca, the $2 \mathrm{~mm}$ fraction of the alga was subjected to autohydrolysis (AH) in a pressurized reactor (Parr Instruments series 4848, Moline, IL, USA) [14] and the liquid extract (liquor) obtained was stored at $-18{ }^{\circ} \mathrm{C}$ until further use. When using the $<0.25 \mathrm{~mm}$ alga fraction, purée-like mixtures were prepared following the procedure already described by the authors [17], with (LoUS) and without ultrasonic treatment (Lo). The alga purées were matured for $24 \mathrm{~h}$ at $4{ }^{\circ} \mathrm{C}$ before preparing the Laminaria-Psyllium gels.

\subsubsection{Preparation of the Laminaria-Psyllium Gels}

The control sample (Psy) was prepared by adding 4\% (w/w, d.b) Psyllium husk (160-315 $\mu \mathrm{m}$ range of particle size) to distilled water at $40{ }^{\circ} \mathrm{C}$ under mechanical stirring (10 $\left.\mathrm{min}, 200 \mathrm{rpm}\right)$ [18]. Another Psyllium gel was prepared in a similar manner as the control by using the Laminaria autohydrolysis liquid extract (PsyL).

Laminaria-Psyllium gels were prepared by mixing (Eurostar Power-b, Ika-Werke, Staufen im Breisgau, Germany) for $5 \mathrm{~min} / 200 \mathrm{rpm}$ at room temperature, the control sample and the alga purée 
mixture at the ratios 25:75, 50:50, and 75:25 in order to obtain visually different structures with potential different applications. Two batches of $160 \mathrm{~g}$ of each gel (Laminaria-Psyllium: 25:75, 50:50, 75:25) were prepared, poured into sealed plastic containers $(\varnothing=10 \mathrm{~cm})$ and stored at $4{ }^{\circ} \mathrm{C}$ for $24 \mathrm{~h}$ to maturate. The schematic procedure of the sample preparation and analysis is presented in Figure 1.

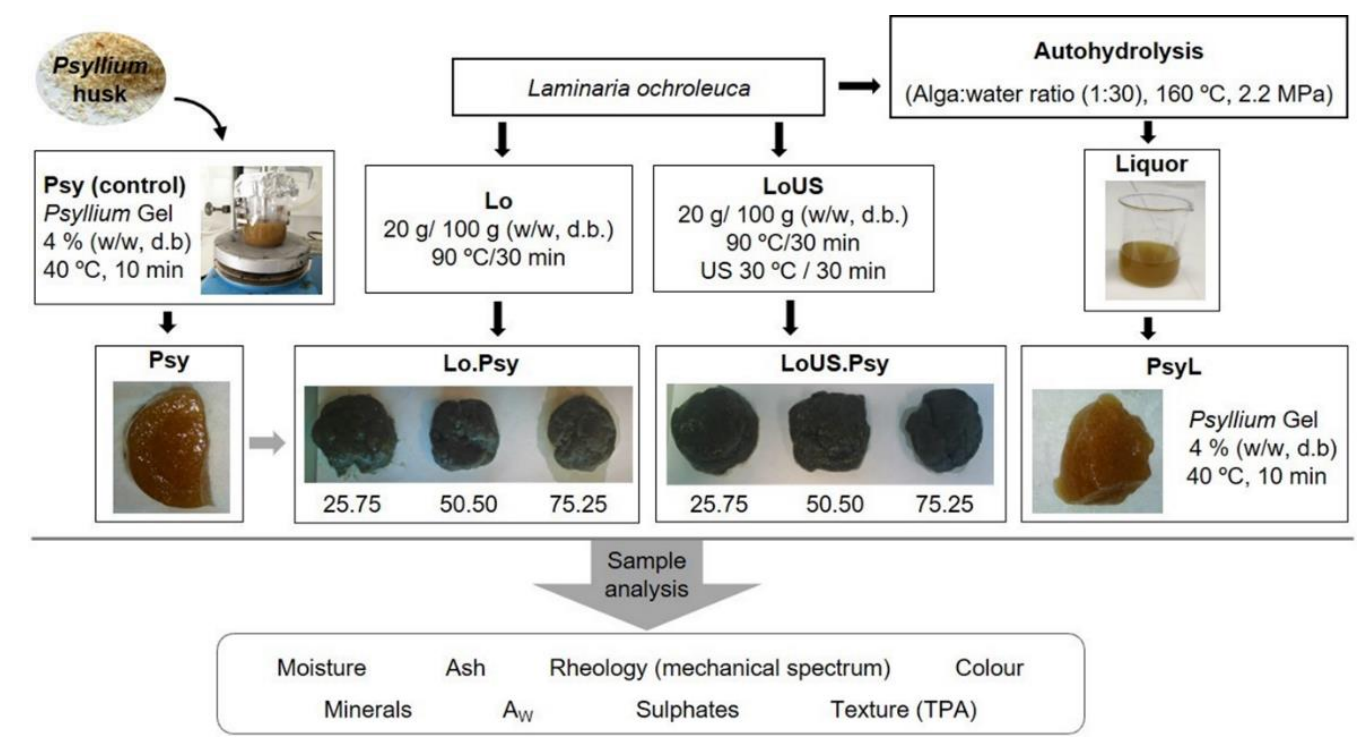

Figure 1. General schematic procedure of the gel preparation and analysis (Lo-Laminaria ochroleuca; Psy—Psyllium gel prepared with water (control); US—ultrasound treatment; PsyL_Psyllium gel prepared with autohydrolysis liquor).

\subsection{Physicochemical Measurements}

Moisture and ash contents of the raw materials and gels were determined by gravimetric methods by placing the samples in an oven $\left(105 \pm 2{ }^{\circ} \mathrm{C}\right)$ until constant weight, or in the furnace $\left(575{ }^{\circ} \mathrm{C}\right.$, $6 \mathrm{~h}$ ) respectively.

Sulfate content of the developed gel samples and Psyllium husk was obtained by the ionic chromatography method (mobile phase: $3.2 \mathrm{mM}$ sodium carbonate/ $1 \mathrm{mM}$ sodium bicarbonate at $0.70 \mathrm{~mL} / \mathrm{min}$ ) as previously reported [19].

Water activity $\left(\mathrm{a}_{\mathrm{W}}\right)$ measurements of all gel samples were performed using a LabMaster-aw (Novasina, Pfäffikon, Switzerland) in triplicate.

Mineral content $(\mathrm{Ca}, \mathrm{K}, \mathrm{Na}, \mathrm{Fe})$ of Psyllium husk was analyzed by inductively coupled plasma optical emission spectrometry (Optima 4300 DV, Perkin Elmer, Waltham, MA, USA) after microwave-assisted (Savillex, Eden Prairie, MN, USA) acid digestion $\left(80^{\circ} \mathrm{C}, 6 \mathrm{~h}\right)$.

\subsection{Color Measurements}

The color evaluation was performed using a CR-400 colorimeter (Minolta, Tokyo, Japan) with standard illuminant $C$. Tristimulus color coordinates (CIELAB system) were used to measure the degree of lightness $\left(\mathrm{L}^{*}\right)$, which ranged from 0 (black) to 100 (white), redness $\left(\mathrm{a}^{*}\right)$ ranging from -60 (green) to +60 (red), and yellowness $\left(b^{*}\right)$ ranging from blue $(-60)$ to yellow $(+60)$. Total color difference $\left(\Delta \mathrm{E}^{*}\right)$ between the samples and the control was calculated according to Equation (1).

$$
\Delta \mathrm{E}^{*}=\left(\Delta \mathrm{L}^{*}+\Delta \mathrm{a}^{*}+\Delta \mathrm{b}^{*}\right)^{1 / 2}
$$

For calibration purposes, a white standard was used $\left(\mathrm{L}^{*}=97.21 ; \mathrm{a}^{*}=0.14 ; \mathrm{b}^{*}=1.99\right)$. Measurements were conducted at $20 \pm 1{ }^{\circ} \mathrm{C}$ and replicated at least five times. 


\subsection{Dynamic Viscoelasticity}

Dynamic oscillatory rheology measurements were used to monitor the viscoelastic characteristics of the gels. Small amplitude oscillatory shear measurements were conducted in triplicate in a controlled stress rheometer (RheoStress 600, Haake, Vreden, Germany) using serrated parallel plate geometry (diameter $35 \mathrm{~mm}$ ) and a $1.5 \mathrm{~mm}$ gap. Surface geometry was covered with paraffin oil to prevent moisture loss. Samples were rested in the rheometer device for $5 \mathrm{~min}\left(20^{\circ} \mathrm{C}\right)$ before rheological testing to temperature equilibration. Initially, stress sweep tests were run at $1 \mathrm{~Hz}$, with the shear stress of the input signal varying from 0.1 to $100 \mathrm{~Pa}$ to find the linear viscoelastic region. The mechanical spectra of all samples were assessed through frequency sweep tests performed from 0.1 to $10 \mathrm{~Hz}\left(20^{\circ} \mathrm{C}, 10 \mathrm{~Pa}\right)$ within the linear viscoelastic region previously defined. Experimental storage $\left(G^{\prime}\right)$ and loss $\left(G^{\prime \prime}\right)$ moduli (Pa) data versus frequency ( $\mathrm{f}, \mathrm{Hz}$ ) were fitted using well-known power models reported elsewhere [20], where $\alpha^{\prime}, \alpha^{\prime \prime}, b^{\prime}$, and $b^{\prime \prime}$ are the corresponding fitting parameters (Equations (2) and (3)).

$$
\begin{aligned}
& G^{\prime}(f)=\alpha^{\prime} f^{b^{\prime}} \\
& G^{\prime \prime}(f)=\alpha^{\prime \prime} f^{b^{\prime \prime}}
\end{aligned}
$$

\subsection{Texture Profile Analysis (TPA)}

Texture profile analysis of all developed gels was performed in a TA-XT2 texturometer (Stable Microsystems, Godalming, UK) with a P0.25S plunger that penetrated $15 \mathrm{~mm}$ into the sample at $1 \mathrm{~mm} / \mathrm{s}$. From the force vs. time texturogram, three parameters were selected to characterize the materials: firmness, as the maximum rupture force $(\mathrm{N})$; adhesiveness, represented by the negative area of the graph, that translates the recessive force of the probe $(\mathrm{N} \cdot \mathrm{s})$; and cohesiveness corresponding to the ratio of the material's response to a second deformation. At least five measurements were made in each sample. Commercial food and feed products were also measured for comparative purposes.

\subsection{Statistical Analysis}

Statistical analysis of the experimental data was performed using RStudio (Version 1.2.1335- C) 2009-2019 RStudio, Inc., Boston, MA, USA), using variance analysis (one-way ANOVA), and the Tukey test, Post Hoc comparison at a significance level of $95 \%(p<0.05)$. A Pearson correlation analysis was also conducted $(p<0.05)$ to determine the relationships between the color, texture parameters, and the amount of alga of the samples. The curve fitting of the rheological data was performed in Excel (version 365, Microsoft). All results are presented as the mean \pm standard deviation (s.d.).

\section{Results and Discussion}

\subsection{Physicochemical Characterization of Samples}

Psyllium gel prepared with autohydrolysis (AH) liquor (PsyL) was visually more fluid than the Psyllium gel prepared with water (control). This is confirmed by texture and rheology measurements, so this issue will be discussed in Sections 3.3 and 3.4.

As seen in Figure 1, the Laminaria-Psyllium 75.25 gel samples presented syneresis (water in the filter paper, not measured) more evident in the sample not submitted to ultrasonic treatment. According to the previous study in which the purée-like mixtures were optimized [17], the authors did not find syneresis in the systems. This could be due to the alga high sodium content that bonds to Psyllium, and at the $25 \%$ ratio was not able to retain all the water in the system, causing the Laminaria-Psyllium 75.25 gels to contract and release part of the water previously enclosed. This phenomenon did not occur in samples with higher Psyllium gel ratios. A recent study by Figueroa and co-workers [21] reported the positive influence of Psyllium on the absence of syneresis of fruit jellies enriched with dietary fiber.

In Table 1, a chemical characterization of Psyllium husk and the developed gels is presented. 
Table 1. Moisture, ash, and sulfate content of Laminaria ochroleuca, Psyllium husk, and the developed gels.

\begin{tabular}{cccc}
\hline Samples & Moisture & Ash & Sulphates \\
\hline & $\mathbf{( \% )}$ & $\mathbf{( \% , \mathbf { d } . \mathbf { b } . )}$ \\
\hline Laminaria ochroleuca [17] & $9.20 \pm 0.07$ & $35.01 \pm 0.31$ & $2.21 \pm 0.10$ \\
\hline Psyllium husk (160-315 $\boldsymbol{\mu m})$ & $9.03 \pm 0.31 \mathrm{~h}$ & $2.98 \pm 0.05 \mathrm{~g}$ & $0.09 \pm 0.00 \mathrm{e}$ \\
\hline Psy (control) & $95.83 \pm 0.08 \mathrm{a}$ & $2.91 \pm 0.18 \mathrm{~g}$ & $0.20 \pm 0.00 \mathrm{e}$ \\
\hline PsyL & $93.58 \pm 0.06 \mathrm{~b}$ & $18.01 \pm 1.83 \mathrm{f}$ & $0.98 \pm 0.00 \mathrm{~d}$ \\
\hline Lo.Psy_25.75 & $91.73 \pm 0.03 \mathrm{c}$ & $24.75 \pm 0.51 \mathrm{~d}$ & $1.75 \pm 0.01 \mathrm{c}$ \\
Lo.Psy_50.50 & $87.50 \pm 0.06 \mathrm{e}$ & $33.08 \pm 0.24 \mathrm{~b}$ & $2.20 \pm 0.07 \mathrm{a}, \mathrm{b}$ \\
Lo.Psy_75.25 & $84.48 \pm 0.22 \mathrm{~g}$ & $36.02 \pm 0.23 \mathrm{a}$ & $1.98 \pm 0.13 \mathrm{~b}, \mathrm{c}$ \\
\hline LoUS.Psy_25.75 & $91.66 \pm 0.12 \mathrm{c}$ & $21.91 \pm 0.71 \mathrm{e}$ & $1.78 \pm 0.02 \mathrm{c}$ \\
LoUS.Psy_50.50 & $87.78 \pm 0.13 \mathrm{~d}$ & $30.34 \pm 0.41 \mathrm{c}$ & $2.14 \pm 0.11 \mathrm{a}, \mathrm{b}$ \\
LoUS.Psy_75.25 & $85.18 \pm 0.12 \mathrm{f}$ & $34.71 \pm 0.37 \mathrm{a}, \mathrm{b}$ & $2.25 \pm 0.01 \mathrm{a}$ \\
\hline
\end{tabular}

Psy (control), Psyllium gels prepared in water; PsyL, Psyllium gels prepared in autohydrolysis liquor; Laminaria-Psyllium gels: Lo.Psy_25.75, Lo.Psy_50.50, and LoPsy_75.25; Laminaria with ultrasonic treatment-Psyllium gels: LoUS.Psy_25.75, LoUS.Psy_50.50, and LoUSPsy_75.25. Data are presented as the mean \pm sd. Different letters in a column show significantly different data values at the $p<0.05$ level.

The moisture content of the Laminaria-Psyllium gels depends greatly on the proportion of both components, and decreased with the increase in Laminaria content. Ash content revealed the reverse trend, with the Laminaria proportion being crucial for the final gel mineral content. This is due to the high ash content $(35 \%$, d.b.) of this alga, as we previously determined [17]. It is also noteworthy that the ultrasonic treatment applied to the puree-like mixtures had a significant $(p<0.05)$ negative influence on the total ash content of the gel, especially in the 25.75 and 50.50 samples.

Sulfate presence in the Laminaria-Psyllium gels is a clear indication of the presence of fucoidan, a sulfated polysaccharide with reported activity against stomach-gastric adenocarcinoma cells and lung carcinoma cells [22].

The most important chemical feature of Psyllium husk is its high soluble fiber content (80\%, d.b., as previously determined by the authors in the same sample [10]. However, aside from its fiber content, Psyllium husk has a mineral composition of $10.3 \mathrm{~g} \mathrm{~K} / \mathrm{kg}, 0.88 \mathrm{~g} \mathrm{Na} / \mathrm{kg}, 1.36 \mathrm{~g} \mathrm{Ca} / \mathrm{kg}$, and $94.7 \mathrm{mg} \mathrm{Fe} / \mathrm{kg}$, (present study), the last two minerals having a higher content than most cooked pulses [23].

Another important feature is Psyllium's ability to retain sodium at physiological important conditions ( $\mathrm{pH}$ 1.2-stomach; $\mathrm{pH}$ 6.8-intestine), being potentially active in reducing the bioavailable fraction of ingested sodium in the body [24].

Considering both the L. ochroleuca [17] and Psyllium husk's mineral content, one can conclude that the partnership between this alga and Psyllium husk could be advantageous for the development of new food products.

Water activity was very high and ranged between $0.999-1.000$ for all samples (data not shown) and these are typical values for gels, although some reduction was expected in gels with a high proportion of Psyllium.

\subsection{Color Evaluation of Samples}

From the color evaluation results presented in Table 2, the Psyllium gels (control and PsyL) only differed in terms of their chromatic parameters, which could be of importance depending on the desired application. 
Table 2. Color parameters $\left(\mathrm{L}^{*}, \mathrm{a}^{*}, \mathrm{~b}^{*}\right)$ and $\Delta \mathrm{E}^{*}$ of Psyllium husk, Laminaria ochroleuca and its AH liquor, and the gels developed.

\begin{tabular}{ccccc}
\hline Samples & $\mathbf{L}^{*}$ & $\mathbf{a}^{*}$ & $\mathbf{b}^{*}$ & $\mathbf{S E}^{*}$ \\
\hline Psyllium husk (160-315 $\boldsymbol{\mu \mathrm { m } )}$ & $59.39 \pm 0.91 \mathrm{a}$ & $6.06 \pm 0.18 \mathrm{a}$ & $24.22 \pm 0.37 \mathrm{a}$ & - \\
\hline Laminaria ochroleuca [17] & $56.36 \pm 0.57$ & $-2.48 \pm 0.04$ & $14.49 \pm 0.18$ & - \\
AH liquor [17] & $31.42 \pm 1.74$ & $1.45 \pm 0.26$ & $2.88 \pm 1.60$ & - \\
\hline Psy (control) & $33.12 \pm 1.78 \mathrm{~b}, \mathrm{c}$ & $1.32 \pm 0.14 \mathrm{c}$ & $9.85 \pm 1.36 \mathrm{c}$ & - \\
PsyL & $35.70 \pm 2.86 \mathrm{~b}$ & $3.78 \pm 1.50 \mathrm{~b}$ & $17.67 \pm 5.54 \mathrm{~b}$ & 8.6 \\
Lo.Psy_25.75 & $30.08 \pm 0.37 \mathrm{c}, \mathrm{d}$ & $-0.16 \pm 0.22 \mathrm{~d}$ & $12.82 \pm 0.57 \mathrm{c}$ & 4.5 \\
Lo.Psy_50.50 & $27.50 \pm 0.77 \mathrm{~d}, \mathrm{e}$ & $-0.07 \pm 0.16 \mathrm{~d}$ & $12.37 \pm 1.07 \mathrm{c}$ & 6.3 \\
Lo.Psy_75.25 & $25.14 \pm 1.70 \mathrm{e}$ & $-0.45 \pm 0.09 \mathrm{~d}$ & $10.90 \pm 1.24 \mathrm{c}$ & 8.2 \\
\hline LoUS.Psy_25.75 & $29.98 \pm 0.82 \mathrm{~d}$ & $-0.06 \pm 0.23 \mathrm{~d}$ & $14.10 \pm 0.46 \mathrm{~b}, \mathrm{c}$ & 5.5 \\
LoUS.Psy_50.50 & $26.96 \pm 1.17 \mathrm{~d}, \mathrm{e}$ & $-0.40 \pm 0.09 \mathrm{~d}$ & $12.38 \pm 1.15 \mathrm{c}$ & 6.9 \\
LoUS.Psy_75.25 & $25.87 \pm 0.55 \mathrm{e}$ & $-0.64 \pm 0.06 \mathrm{~d}$ & $11.60 \pm 1.14 \mathrm{c}$ & 7.7 \\
\hline
\end{tabular}

Psy (control), Psyllium gels prepared in water; PsyL, Psyllium gels prepared in autohydrolysis liquor; Laminaria-Psyllium gels: Lo.Psy_25.75, Lo.Psy_50.50, and LoPsy_75.25; Laminaria with ultrasonic treatment-Psyllium gels: LoUS.Psy_25.75, LoUS.Psy_50.50, and LoUSPsy_75.25. Data are presented as the mean \pm sd. Different letters in the same column correspond to significant differences $(p<0.05)$.

As expected, the lightness $\left(\mathrm{L}^{*}\right)$ of the gel samples decreased with the incorporation of Laminaria, although significant differences were only registered between the Laminaria-Psyllium 25.75 and Laminaria-Psyllium 75.25 samples. It is noteworthy that the color parameters of the gel samples with the highest Laminaria content were like those obtained in the purée-like mixtures [14]. Moreover, the color parameters $\mathrm{L}^{*}$ (Lo.Psy: $\mathrm{r}=-0.928, p=1.3 \times 10^{-9}$; LoUS.Psy: $\mathrm{r}=-0.920, p=9.3 \times 10^{-9}$ ) and $\mathrm{a}^{*}$ (Lo.Psy: $\mathrm{r}=-0.849 ; p=1.2 \times 10^{-6}$; LoUS.Psy: $\mathrm{r}=-0.913, p=2.0 \times 10^{-8}$ ) were strongly negatively correlated with Laminaria content in the gel formulations.

The $\Delta \mathrm{E}^{*}$ between the Laminaria-Psyllium gels and the control ranged from 4.5 to 8.2 , increasing with the increase in the Laminaria content in the system. These values indicate that the consumer would distinguish between the two samples compared [25].

It should be pointed out that the gels proposed here are not finished products. In this sense, the color of the final food gel product could be optimized by considering these findings and according to the desired final color.

\subsection{Effect of Laminaria-Psyllium Ratio on the Dynamic Viscoelasticity}

Figure 2 shows the elastic behavior of Laminaria-Psyllium gel systems. As the alga fraction increased, a structuring effect was observed in the gels. This behavior was markedly noticed in the highest alga concentration (Lo.Psy_75.25 and LoUS.Psy_75.25). This interaction is probably due to physical entanglements between the polymers present in both the alga and Psyllium, causing the reinforcement of the gel. However, in the absence of the Psyllium gel, the alga purees showed a huge decrease in $G^{\prime}$ to values similar to the control (Psy), but more frequency dependent $\left(b^{\prime}=0.209\right)$ [17].

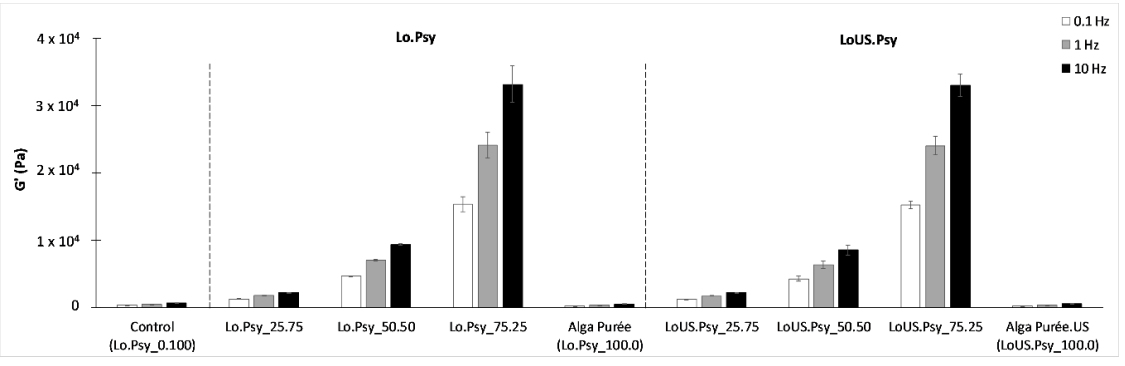

Figure 2. Elastic modulus at $0.1 \mathrm{~Hz}, 1 \mathrm{~Hz}$, and $10 \mathrm{~Hz}$ of Laminaria-Psyllium gels with (LoUS.Psy) and without ultrasonic treatment (Lo.Psy), control, and Laminaria purées (Alga Purée; Alga Purée.US) [17]. 
This synergistic interaction was also found in other polymeric systems, namely between the locust bean gum (LBG) and xanthan gum, where the latter did not form gel, rather a shear-thinning solution, but combined with LBG to form a strong gel structure [26].

The mechanical spectra of the developed gels are depicted in Figure 3.

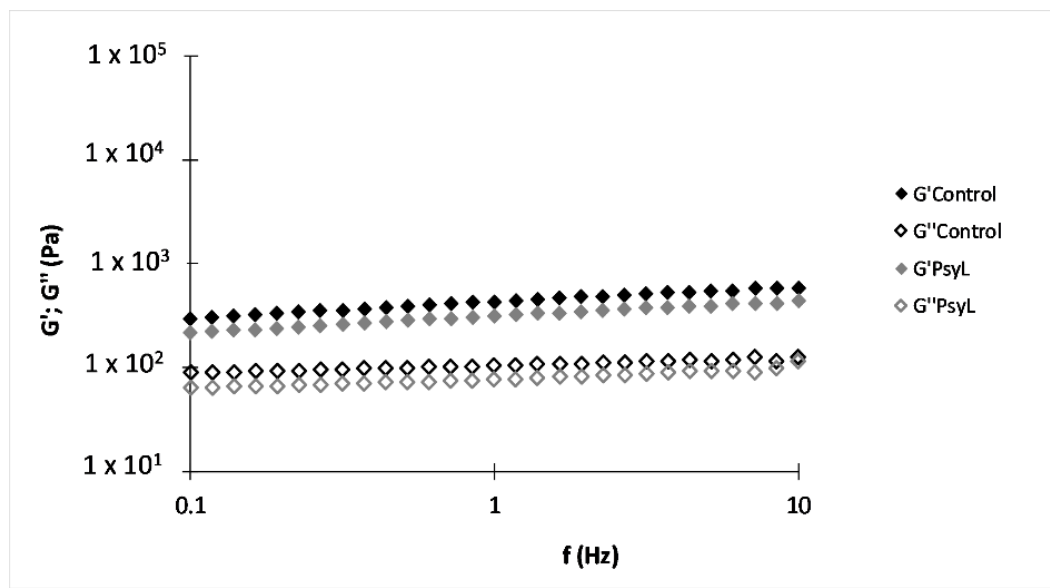

(a)

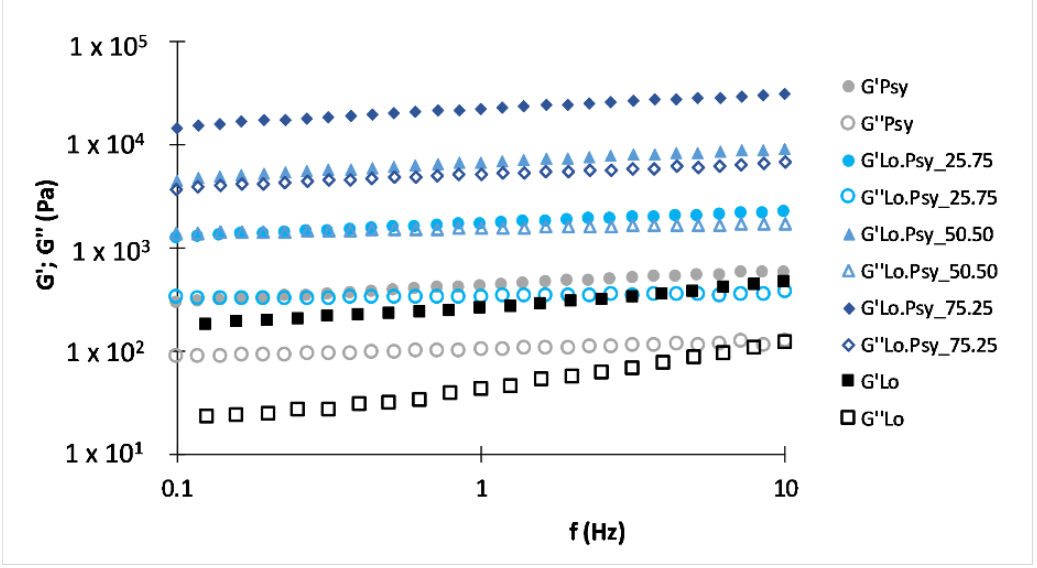

(b)

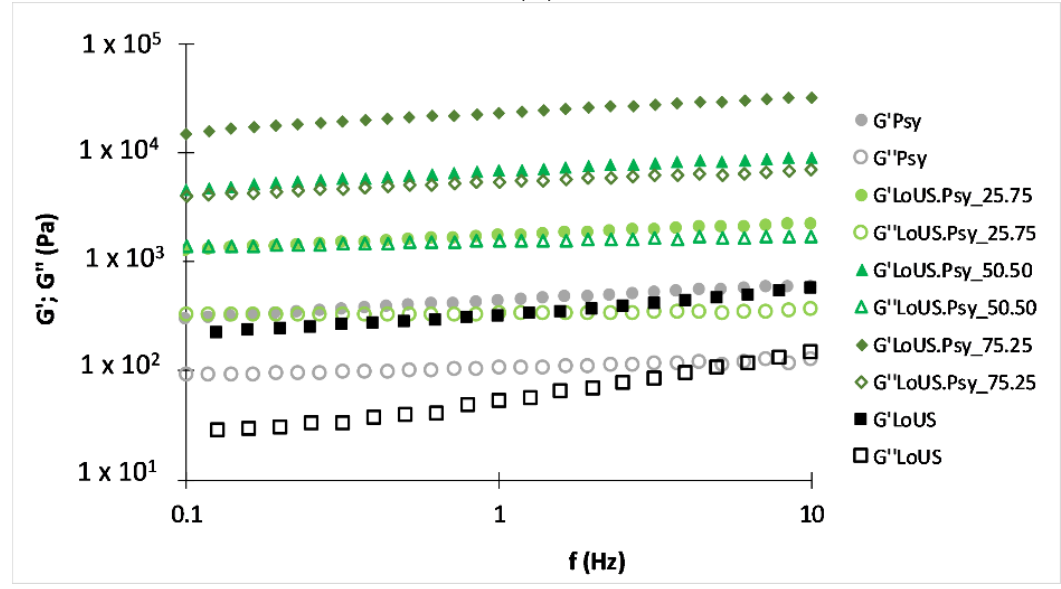

(c)

Figure 3. Mechanical spectra of the Psyllium gels prepared in water (control) and autohydrolysis liquor (PsyL).(a) Laminaria-Psyllium gels (Lo.Psy_25.75, Lo.Psy_50.50, LoPsy_75.25); (b) Laminaria with ultrasonic treatment-Psyllium gels (LoUS.Psy_25.75, LoUS.Psy_50.50, LoUSPsy_75.25; (c) $\mathrm{G}^{\prime}$, closed symbol; $\mathrm{G}^{\prime \prime}$, open symbol. 
To quantify the impact of the different combinations of Laminaria and Psyllium on the viscoelastic moduli, the variation of $G^{\prime}$ and $G^{\prime \prime}$ with gel composition was obtained from the respective mechanical spectra (Table 3).

Table 3. Power law parameters $\left(\alpha^{\prime}, \alpha^{\prime \prime}, b^{\prime}\right.$, and $\left.b^{\prime \prime}\right)$ of the gel samples with Laminaria ochroleuca and Psyllium husk, control, and PsyL.

\begin{tabular}{ccccc}
\hline Samples & \multicolumn{2}{c}{$\mathrm{G}^{\prime}$} & $\mathbf{b}^{\prime}$ & $\mathbf{G}^{\prime \prime}$ \\
\hline Psy (Control) & $436.8 \pm 15.4$ & $0.153 \pm 0.002$ & $104.8 \pm 7.0$ & $0.071 \pm 0.011$ \\
PsyL & $323.0 \pm 18.2$ & $0.149 \pm 0.005$ & $79.6 \pm 2.4$ & $0.090 \pm 0.005$ \\
\hline Lo.Psy_25.75 & $1689.3 \pm 20.8$ & $0.124 \pm 0.000$ & $344.2 \pm 2.7$ & $0.022 \pm 0.000$ \\
Lo.Psy_50.50 & $6819.9 \pm 103.8$ & $0.148 \pm 0.002$ & $1584.5 \pm 28.3$ & $0.049 \pm 0.002$ \\
Lo.Psy_75.25 & $0.5 \pm 1816.6$ & $0.158 \pm 0.002$ & $5485.0 \pm 434.5$ & $0.119 \pm 0.001$ \\
\hline LoUS.Psy_25.75 & $1681.6 \pm 3.5$ & $0.121 \pm 0.000$ & $331.9 \pm 2.8$ & $0.019 \pm 0.000$ \\
LoUS.Psy_50.50 & $6239.3 \pm 543.3$ & $0.146 \pm 0.002$ & $1442.5 \pm 122.0$ & $0.049 \pm 0.001$ \\
LoUS.Psy_75.25 & $23,533.5 \pm 1267.8$ & $0.159 \pm 0.001$ & $5530.1 \pm 331.8$ & $0.116 \pm 0.002$ \\
\hline
\end{tabular}

The goodness of fitting $\left(R^{2}\right)$ ranged from $0.995-0.997$ for $\mathrm{G}^{\prime}$ and from $0.936-0.997$ for $\mathrm{G}^{\prime \prime}$.

The mechanical spectra Psy (control) and PsyL exhibited similar viscoelastic performance typical of well-structured weak gels, with slight frequency dependence (Figure 3a). This result is consistent with the rheological study by Haque et al. [27], in which it is also reported that Psyllium husk forms gel even at low temperature, this being an important feature to consider in food design. Moreover, the developed gels were more stable at higher frequencies than the ones produced with $10-15 \%$ chia flour at $90^{\circ} \mathrm{C}$ (Ramos et al., 2016), reinforcing Psyllium's potential as a valuable and sustainable biopolymer.

As mentioned earlier, PsyL appeared to be more fluid than the control (Psy), which was confirmed by the mechanical spectra, with both viscoelastic moduli of the control being higher than those of PsyL, and by the decrease of $\alpha^{\prime}$ (Table 3). Autohydrolysis promotes the solubilization of minerals [17] and the depolymerization of polysaccharides, namely alginate, fucoidan, and laminarin present in brown algae [28], rendering a liquid extract with an acidic $\mathrm{pH}(\approx 5,[19])$. Since Laminaria liquid extract is a multicomponent matrix, its effect on the Psyllium gel properties are more complex, depending not only on the solution $\mathrm{pH}$, but also on the type of ions in the solution, and even on the presence of peptides and other molecules resulting from the depolymerization of the polysaccharides. These polymer fractions can interfere with the gel matrix and exert an antagonism, leading to the reduction of gel links and de-structuring the material.

The ultrasonic pre-treatment applied to L. ochroleuca did not affect the rheological behavior of the Laminaria-Psyllium gels. The weak-gel like behavior was maintained in all Laminaria-Psyllium gel samples, and was more noticeable as the alga fraction increased, as can be observed by the increase in the $b^{\prime}$ parameter of the resulting power law (Table 3). As the incorporation of the alga solid fraction increased, the dependence of the material on frequency increased; however the value of the viscoelastic moduli increased probably due to the reduction of the number of links, but also stronger ones, which may be due to interactions between the alginate from the alga and fiber from the Psyllium husk reinforced by calcium ions [29].

\subsection{Texture Properties of the Laminaria-Psyllium Gel Systems}

Texture is a major quality parameter, and is crucial for consumer acceptance. Figure 4 presents the texture profiles of the samples and the commercial references. 


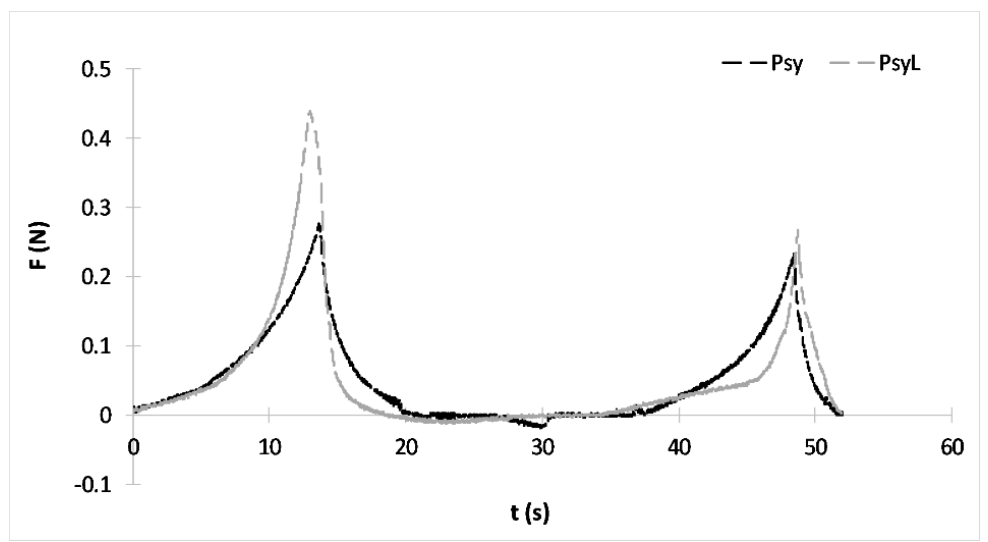

(a)

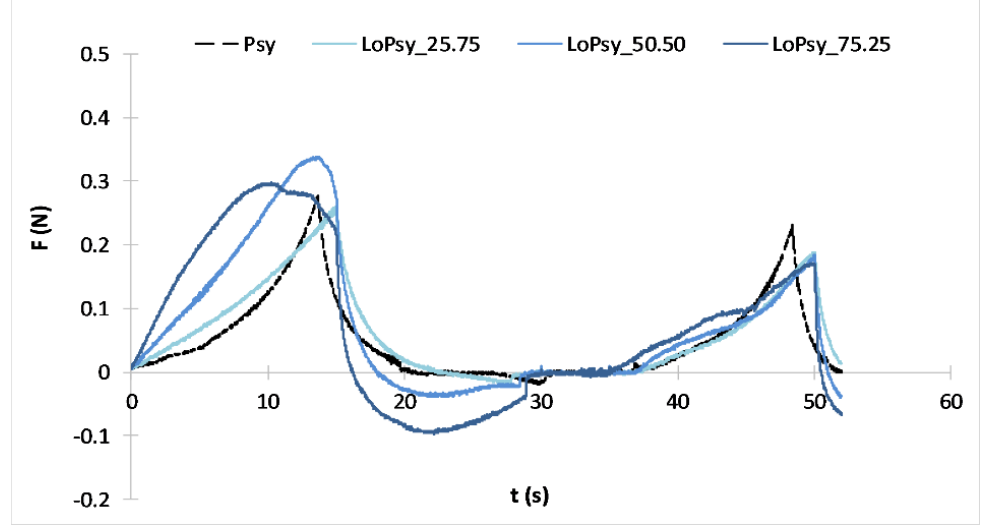

(b)

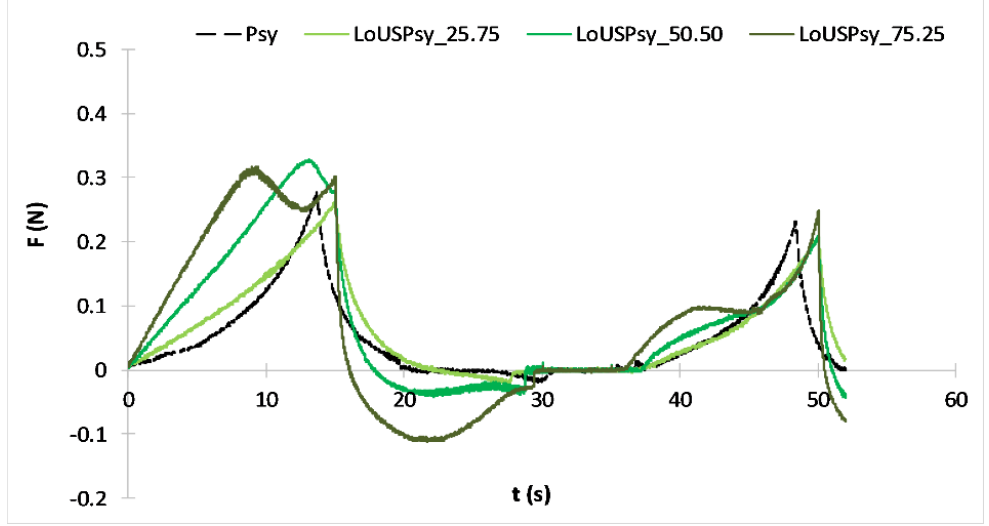

(c)

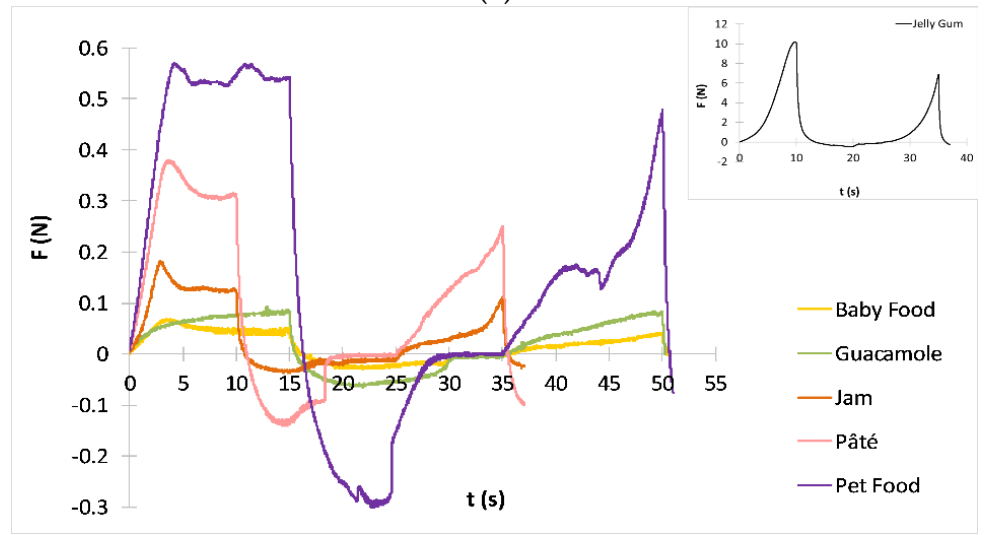

(d)

Figure 4. Texture profiles of Psy (control) and PsyL (a), Laminaria-Psyllium gels (b), Laminaria-Psyllium gels subjected to ultrasonic treatment (c), and commercial products (d). The differences in the texturograms reflect the different sizes and shapes of the commercial products. 
Each food system (e.g., jelly, mayonnaise, and baby food) presents texture properties that are specific, easily recognizable, and desired by the consumers. Despite the information given by the texture profile, the use of this methodology is very limited in the scientific literature. To our knowledge, no published studies refer to the texture features of commercial gelled products, therefore we show here some texture profiles of different commercial food products to illustrate the data for these systems to be used as a target for further product development. Based on these texture profiles (Figure 4d), three groups of samples can be discriminated: one composed of Pâté, Pet Food and Jam; another with Baby Food and Guacamole; and a third with Jelly Gum, whose graph is shown separately. In the first group of samples, the rupture point occurred at a low break distance, and the force reached a plateau until the probe retracted from the sample. This mechanical behavior was similar to what we found in LoUS.Psy_75.25 (Figure 4c) and has also been reported by Genovese and co-workers [30] for pectin gels. The control and PsyL texture profiles (Figure 4a) were similar to the one obtained by Figueroa et al. [21] for fruit jellies with Psyllium, although with much lower magnitude.

From the texture profiles depicted, the firmness, adhesiveness, and cohesiveness values were calculated (Table 4).

Table 4. Texture parameters (firmness, adhesiveness and cohesiveness) of the gels developed and commercial references.

\begin{tabular}{ccccc}
\hline \multicolumn{2}{c}{ Samples } & Firmness (N) & Adhesiveness (N.s) & Cohesiveness \\
\hline & Psy (control) & $0.296 \pm 0.036 \mathrm{c}, \mathrm{d}, \mathrm{e}$ & $-0.034 \pm 0.006 \mathrm{a}$ & $0.581 \pm 0.051 \mathrm{~b}$ \\
& PsyL & $0.419 \pm 0.031 \mathrm{~b}, \mathrm{c}$ & $-0.032 \pm 0.003 \mathrm{a}$ & $0.453 \pm 0.024 \mathrm{c}, \mathrm{d}, \mathrm{e}$ \\
\cline { 2 - 5 } Developed gel & Lo.Psy_25.75 & $0.259 \pm 0.028 \mathrm{c}, \mathrm{d}, \mathrm{e}$ & $-0.040 \pm 0.012 \mathrm{a}$ & $0.517 \pm 0.037 \mathrm{~b}, \mathrm{c}$ \\
samples & Lo.Psy_50.50 & $0.316 \pm 0.020 \mathrm{c}, \mathrm{d}, \mathrm{e}$ & $-0.274 \pm 0.038 \mathrm{a}$ & $0.362 \pm 0.044 \mathrm{e}, \mathrm{f}, \mathrm{g}$ \\
& Lo.Psy_75.25 & $0.279 \pm 0.039 \mathrm{c}, \mathrm{d}, \mathrm{e}$ & $-0.977 \pm 0.075 \mathrm{c}$ & $0.403 \pm 0.026 \mathrm{~d}, \mathrm{e}, \mathrm{f}$ \\
\cline { 2 - 5 } & LoUS.Psy_25.75 & $0.261 \pm 0.007 \mathrm{c}, \mathrm{d}, \mathrm{e}$ & $-0.069 \pm 0.017 \mathrm{a}$ & $0.538 \pm 0.009 \mathrm{~b}, \mathrm{c}$ \\
& LoUS.Psy_50.50 & $0.333 \pm 0.026 \mathrm{~b}, \mathrm{c}, \mathrm{d}$ & $-0.268 \pm 0.042 \mathrm{a}$ & $0.354 \pm 0.028 \mathrm{f}, \mathrm{g}$ \\
& LoUS.Psy_75.25 & $0.319 \pm 0.024 \mathrm{c}, \mathrm{d}, \mathrm{e}$ & $-0.978 \pm 0.047 \mathrm{c}$ & $0.391 \pm 0.030 \mathrm{~d}, \mathrm{e}, \mathrm{f}, \mathrm{g}$ \\
\hline Commercial & Baby Food & $0.065 \pm 0.008 \mathrm{~d}, \mathrm{e}$ & $-0.325 \pm 0.034 \mathrm{a}, \mathrm{b}$ & $0.475 \pm 0.023 \mathrm{c}, \mathrm{d}$ \\
products & Jelly Gum & $10.314 \pm 0.386 \mathrm{a}$ & $-3.596 \pm 0.562 \mathrm{e}$ & $0.330 \pm 0.028 \mathrm{f}, \mathrm{g}$ \\
& Guacamole & $0.091 \pm 0.011 \mathrm{e}$ & $-0.638 \pm 0.106 \mathrm{~b}, \mathrm{c}$ & $0.748 \pm 0.075 \mathrm{a}$ \\
& Jam & $0.182 \pm 0.003 \mathrm{c}, \mathrm{d}, \mathrm{e}$ & $-0.298 \pm 0.015 \mathrm{a}$ & $0.310 \pm 0.015 \mathrm{~g}$ \\
& Pâté & $0.364 \pm 0.032 \mathrm{~b}, \mathrm{c}$ & $-0.854 \pm 0.081 \mathrm{c}$ & $0.464 \pm 0.038 \mathrm{c}, \mathrm{d}$ \\
& Pet Food & $0.587 \pm 0.066 \mathrm{~b}$ & $-2.173 \pm 0.148 \mathrm{~d}$ & $0.371 \pm 0.024 \mathrm{e}, \mathrm{f}, \mathrm{g}$ \\
\hline
\end{tabular}

Psy (control), Psyllium gels prepared in water; PsyL, Psyllium gels prepared in autohydrolysis liquor; Laminaria-Psyllium gels: Lo.Psy_25.75, Lo.Psy_50.50, and LoPsy_75.25; Laminaria with ultrasonic treatment-Psyllium gels: LoUS.Psy_25.75, LoUS.Psy_50.50, and LoUSPsy_75.25. Data are presented as the mean \pm sd. Different letters in the same column correspond to significant differences $(p<0.05)$.

In general, it can be said that the firmness of the Laminaria-Psyllium system is independent of the level of Laminaria incorporation and the ultrasonic (US) pre-treatment. On the other hand, there are strong negative correlations between the adhesiveness $(\mathrm{r}=-0.888, p<0.05)$ and cohesiveness $(\mathrm{r}=-0.844, p<0.05)$ parameters and Laminaria concentration, and again, the US pre-treatment did not make any change. The fact that adhesiveness can be adjusted by keeping the firmness values constant could be useful in product development.

In a previous study by the authors [17], it was found that the texture parameters, especially adhesiveness, of the alga purée-like mixtures varied according to the ultrasonic treatment. However, that difference was not maintained after the addition of Psyllium. Since PsyL did not show adhesiveness values that could explain this result, one can conclude that there is a synergistic effect of Laminaria and Psyllium in this texture parameter, stronger than mere addition. Based on these results and looking at the texture profiles of the samples (Figure $4 a-c$ ), one can conclude that the texture properties of Laminaria-Psyllium gels are governed by the alga, what is in agreement with the dynamic rheology results. Texture profiles (Figure 4) confirm the relevance of alga in the system. 
The texture parameters of the commercial products varied greatly. Comparing the texture parameters of the gelled systems developed with those of the references (Table 4), the developed Laminaria-Psyllium gels presented similar values to the commercial products. Although the systems developed are not finished products, but binary systems consisting of alga purée and Psyllium gel, this is a good starting point for the development of enriched gelled food products. These Laminaria and Psyllium whole materials can be used as alternatives to the biopolymers that are usually added to build up structure in foods. This is in line with the food trends regarding the use of natural products over processed ones.

It should be pointed out that in this approach, we developed the Laminaria-Psyllium gels using water, but the gels could also be produced in the same way using the AH liquor extract, thus taking advantage of the soluble compounds present there, namely phenolic compounds with antioxidant capacity [17]. Due to the differences in texture and rheological features between the control and PsyL, it is plausible to assume that Laminaria-Psyllium gels prepared in AH liquor would present distinct mechanical properties.

\section{Conclusions}

Food gels were developed with Laminaria and Psyllium husk, adding value to both these natural resources. Psyllium husk interacted positively with this alga, reinforcing the viscoelastic behavior of the obtained gels. These novel functional gels with minimal processing can be a starting point to the development of several food and feed applications.

Food application studies are in progress to evaluate the demonstrated potential of this Laminaria-Psyllium partnership.

Author Contributions: P.F., M.D.T., and A.R. conceived and planned the experiments. P.F. and M.D.T. participated in the sample preparation and analysis, data analysis and interpretation of the results, and writing of the manuscript with input from all authors. I.S., A.R., and H.D. supervised the research work, contributed to the discussion of the data, and revised the manuscript. All authors contributed with suggestions and comments for the final version of the manuscript.

Funding: The authors are grateful to the Spanish Ministry of Economy and Competitiveness CTM2015-68503-R). M.D.T. thanks the Spanish Ministry of Economy and Competitiveness for her postdoctoral grant (IJCI-2016-27535). P.F. acknowledges her PhD grant from the Universidade de Lisboa (C0144M) and ERASMUS+ grant. The authors are also grateful to Fundação para a Ciência e a Tecnologia (Portugal) through the research unit UID/AGR/04129/2013 (LEAF) financial support.

Conflicts of Interest: The authors declare no conflict of interest.

\section{References}

1. Kim, S.-K.; Bhatnagar, I. Physical, Chemical, and Biological Properties of Wonder Kelp—Laminaria. In Advances in Food and Nutrition Research; Kim, S.-K., Ed.; Elsevier Inc.: Amsterdam, The Netherlands, 2011; pp. 85-96. [CrossRef]

2. Adebisi, A.O.; Laity, P.R.; Conway, B.R. Formulation and evaluation of floating mucoadhesive alginate beads for targeting Helicobacter pylori. J. Pharm. Pharmacol. 2015, 67, 511-524. [CrossRef] [PubMed]

3. Oliveira, S.; Fradinho, P.; Mata, P.; Moreira-Leite, B.; Raymundo, A. Exploring innovation in a traditional sweet pastry: Pastel de Nata. Int. J. Gastron. Food Sci. 2019, 17, 100160. [CrossRef]

4. Sánchez-Machado, D.I.; López-Cervantes, J.; López-Hernández, J.; Paseiro-Losada, P. Fatty acids, total lipid, protein and ash contents of processed edible seaweeds. Food Chem. 2004, 85, 439-444. [CrossRef]

5. Fernandes, F.; Barbosa, M.; Oliveira, A.P.; Azevedo, I.C.; Sousa-Pinto, I.; Valentão, P.; Andrade, P.B. The pigments of kelps (Ochrophyta) as part of the flexible response to highly variable marine environments. J. Appl. Phycol. 2016, 28, 3689-3696. [CrossRef]

6. Parada, J.; Pérez-Correa, J.R.; Pérez-Jiménez, J. Design of low glycemic response foods using polyphenols from seaweed. J. Funct. Foods. 2019, 56, 33-39. [CrossRef]

7. Andrade, P.B.; Barbosa, M.; Matos, R.P.; Lopes, G.; Vinholes, J.; Mouga, T.; Valentão, P. Valuable compounds in macroalgae extracts. Food Chem. 2013, 138, 1819-1828. [CrossRef] 
8. Roohinejad, S.; Koubaa, M.; Barba, F.J.; Saljoughian, S.; Amid, M.; Greiner, M. Application of seaweeds to develop new food products with enhanced shelf-life, quality and health-related beneficial properties. Food Res. Int. 2017, 99, 1066-1083. [CrossRef]

9. FDA. CFR-code of federal regulations title 21. U.S. Food and Drug Administration. 2012. Available online: http://www.accessdata.fda.gov/scripts/cdrh/cfdocs/cfcfr/CFRSearch.cfm?fr=101.81 (accessed on 26 July 2019).

10. Raymundo, A.; Fradinho, P.; Nunes, M.C. Effect of Psyllium fibre content on the textural and rheological characteristics of biscuit and biscuit dough. Bioact. Carbohydr. Dietary Fibre. 2014, 3, 96-105. [CrossRef]

11. Fischer, M.H.; Yu, N.; Gray, G.R.; Ralph, J.; Anderson, L.; Marlett, J.A. The gel-forming polysaccharide of psyllium husk (Plantago ovata Forsk). Carbohyd. Res. 2004, 339, 2009-2017. [CrossRef]

12. Askari, F.; Sadeghi, E.; Mohammadi, R.; Rouhi, M.; Taghizadeh, M.; Shirgardoun, M.H.; Kariminejad, M. The physicochemical and structural properties of psyllium gum/modified starch composite edible film. J. Food Process Preserv. 2018, 42, 13715. [CrossRef]

13. Singh, B. Psyllium as therapeutic and drug delivery agent. Int. J. Pharm. 2007, 334, 1-14. [CrossRef] [PubMed]

14. Ramos, S.; Fradinho, P.; Mata, P.; Raymundo, A. Assessing gelling properties of chia (Salvia hispanica L.) flour through rheological characterization. J. Sci. Food Agric. 2016, 97, 1753-1760. [CrossRef] [PubMed]

15. Soukoulis, C.; Cambier, S.; Serchi, T.; Tsevdou, M.; Gaiani, C.; Ferrer, P.; Taoukis, P.S.; Hoffmann, L. Rheological and structural characterisation of whey protein acid gels co-structured with chia (Salvia hispanica L.) or flax seed (Linum usitatissimum L.) mucilage. Food Hydrocolloid. 2019, 89, 542-553. [CrossRef]

16. Soukoulis, C.; Gaiani, C.; Hoffmann, L. Plant seed mucilage as emerging biopolymer in food industry applications. Curr. Opin. Food Sci. 2018, 22, 28-42. [CrossRef]

17. Fradinho, P.; Flórez-Fernández, N.; Sousa, I.; Raymundo, A.; Domínguez, H.; Torres Pérez, M.D. Environmentally friendly processing of Laminaria ochroleuca for soft food applications with bioactive properties. J. Appl. Phycol. 2019. accepted for publication.

18. Fradinho, P.; Sousa, I.; Raymundo, A. The role of Psyllium gels on the structuring of gluten-free fresh pasta -a rheological approach. In Book of Abstracts of AERC 2019. Proceedings of the Oral Communication FP11, Portoröz, Slovenia, 8-11 April 2019; The European Society of Rheology: Zurich, Switzerland, 2019; p. 29.

19. Gómez-Ordóñez, E.; Jiménez-Escrig, A.; Rupérez, P. Dietary fibre and physicochemical properties of several edible seaweeds from the northwestern Spanish coast. Food Res. Int. 2010, 43, 2289-2294. [CrossRef]

20. Paraskevopoulou, A.; Kiosseoglou, V.; Alevisopoulos, S.; Kasapis, S. Small deformation properties of model salad dressings prepared with reduced cholesterol egg yolk. J. Texture Stud. 1997, 28, 221-237. [CrossRef]

21. Figueroa, L.E.; Genovese, D.B. Fruit jellies enriched with dietary fibre: Development and characterization of a novel functional food product. LWT Food Sci. Technol. 2019, 111, 423-428. [CrossRef]

22. Flórez-Fernández, N.; Torres, M.D.; González-Muñoz, M.J.; Domínguez, H. Recovery of bioactive and gelling extracts from edible brown seaweed Laminaria ochroleuca by non-isothermal autohydrolysis. Food Chem. 2019, 277, 353-361. [CrossRef]

23. Margier, M.; Georgé, S.; Hafnaoui, N.; Remond, D.; Nowicki, M.; Du Chaffaut, L.; Amiot, M.-J.; Reboul, E. Nutritional Composition and Bioactive Content of Legumes: Characterization of Pulses Frequently Consumed in France and Effect of the Cooking Method. Nutrients 2018, 10, 1668. [CrossRef]

24. Jimoh, M.A.; MacNaughtan, W.; Williams, H.E.L.; Greetham, D.; Linforth, R.L.; Fisk, I.D. Sodium ion interaction with psyllium husk (Plantago sp.). Food Funct. 2016, 7, 4041. [CrossRef] [PubMed]

25. Castellar, M.R.; Obón, J.M.; Fernández-López, J.A. The isolation and properties of a concentrated red-purple betacyanin food colorant from Opuntia stricta fruits. J. Sci. Food Agric. 2006, 86, 122-128. [CrossRef]

26. Copetti, G.; Grassi, M.; Lapasin, R.; Pricl, S. Synergistic gelation of xanthan gum with locust bean gum: A rheological investigation. Glycoconj. J. 1997, 14, 951-961. [CrossRef] [PubMed]

27. Haque, A.; Richardson, R.K.; Morris, E.R.; Dea, I.C.M. Xanthan-like 'weak gel' rheology from dispersions of ispaghula seed husk. Carbohyd. Polym. 1993, 22, 223-232. [CrossRef]

28. Rodríguez-Jasso, R.M.; Mussatto, S.I.; Pastrana, L.; Aguilar, C.N.; Teixeira, J.A. Extraction of sulfated polysaccharides by autohydrolysis of brown seaweed Fucus vesiculosus. J. Appl. Phycol. 2013, 25, 31-39. [CrossRef] 
29. Guo, Q.; Cui, S.W.; Wang, Q.; Goff, H.D.; Smith, A. Microstructure and rheological properties of psyllium polysaccharide gel. Food Hydrocolloid. 2009, 23, 1542-1547. [CrossRef]

30. Genovese, D.B.; Ye, A.; Singh, H. High Methoxyl Pectin/Apple Particles Composite Gels: Effect of Particle Size and Particle concentration on Mechanical Properties and Gel Structure. J. Text Stud. 2010, 41, 171-189. [CrossRef] 